\title{
Micrandropsis, novo gênero de Euphorbiaceae da Amazônia
}

\author{
WILliam A. RODRIGUES(") \\ Instituto Nacional de Pesquisas \\ da Amazônia
}

\begin{abstract}
SINOPSE
O autor propõe neste trabalho um novo gênero de Euphorbiaceae denominado Micrandropsis W. Rodr., cuja espécie típica é Micrandopsis scleroxylon (W. Rođr.) W. Rođr., uma árvore amazônica relati. vamente frequiente nas matas de terra firme das cercanias de Manaus, Amazonas.
\end{abstract}

\section{INTRODUÇÃo}

Quando descrevi Micrandra scleroxylon W. Rodr., estava mais ou menos convicto de que esta espécie poderia eventualmente pertencer a um novo gênero, porém, faltavam-me melhore estudos a respeito, razão pela qual só agora está sendo proposto.

O novo gênero é bastante próximo de Micrandra Bentham, do qual se distingue principalmente pela forma da antera e características da madeira, conforme descrição apresentada pelo autor em trabalho anterior (1971).

Micrandropsis, seguindo o sistema de classificação adotado por Pax \& Hoffmann (1931) e jablonski (1967), se enquadra dentro da confusa e desatualizada tribo Geloniae M. Arg. ou do complexo Hevea-Micrandra-Joannesia, segundo Schultes (1955 e 1956).

Embora não se conheçam estudos químicos em madeiras de Micrandra e gêneros afins, amostras de tronco de Micrandropsis scleroxyIon enviadas para análise química, segundo Alvarenga \& Gottlieb (1972), assinalaram pela primeira vez a ocorrência natural em madeira de "fenantrenos diterpenoidais, tais como 2.6- dihidroxi-1,7-dimetilfenantreno e outras substâncias estruturalmente afins, descoberta esta, quiçá, de grande valia na caracterização quimiotaxonômica do novo gênero a seguir descrito.

\section{Micrandropsis W. Rodr., nov. gen.}

Arbor monoica, latice exiguo, ligno durisisisimo duramine fusco-brunneo alburni bene distincto. Folia simplicia, petiolata, oblonga vel oblongo-lanceolata, subcoriacea, glabra, integra, ad apicem distincte mucronata, juxta basin láminae uniglandulosa vel vix biglandulosa (glandula verruciformis crassa). Inflorescencia terminalis et axillaris, paniculata, longiramosa folia saepe superans; bractea ad basin glandulosa. Flores unisexuales subinde hermaphroditi; calyx quinquepartitus, laciniis subaequalibus, imbricatis; corolla nulla; stamina libera 5-7, saepius 5, antheris linearibus; discus florum staminiferum quinquelobatus; ovarium ovoideum, sericeum, triloculare, disco hypogyno annulari tenuissimo instructum; stilo subsessili tripartido applanato cum divisionibus bifidis ad basin distincte connatis. Fructus pedicellatus, dehiscens, subgloboso-trigastricus, siccitatate epicarpio rugoso; semina ovata, carunculata leviter compressa, albuminosa, cotyledonibus subsessilibus, planis et latis.

Typus et species unica: Micrandropsis scleroxylon (W. Rodr.) W. Rodr. Synon. : Micrandra scleroxylon W. Rodr., in Acta Amazonica 1 (3): 3-8, fig. 1-4. 1971.

(*) - Bolsista do Conselho Nacional de Pesquisas. 


\section{SUMTMARY}

Micrandropsis W. Rodrigues is proposed in this paper as a new Euphorbiaceae genus, of which the typic species is Micrandropsis sclerorylon (W. Rodr.) W. Rodr., a common amazonian tree from the upland forest around Manaus, Amazonas.

\section{BIBLIOGRAFIA CITADA}

ALyArenga, M. \& GotTlLier, O. R.

1972 - Os fenantrenos de Micrandra scleroxylon, in Ciência e Cultura 24 (2): 132-133.
Pax, F. \& Hoffmann, K.

1931 - Euphorbiaceae, in Engler \& Plant, Nat. Pflanzenfamilien, $2^{\mathrm{a}} \mathrm{ed}$., $19 \mathrm{c}: 11-233$.

RODRIGUES, W. A.

1971 - Micrandra scleroxylon W. Rodr., nova Euforbiácea da Amazónia Brasileira. Acta Amazo. rica $I(3): 3-8$, figs, $1-4$

SChultes, R. E.

1955 - A new generic concept in the Euphorbiaceae. Bot. Mus. Leaflets, Harvard Univ., 17(1) : 27-36.

1956 - The amazonian indian and evolution in Hevea and related genera. Journ. Arnold Arboretum $37(2): 123-147$.

Aceito para publicação em $23 / 7 / 73$ 